\title{
Psychometric properties of the Basic Empathy Scale in Polish children and adolescents
}

\author{
Izabela Zych ${ }^{1}$ (D) David P. Farrington ${ }^{2} \cdot$ Elena Nasaescu $^{1} \cdot$ Darrick Jolliffe $^{3} \cdot$ Estera Twardowska-Staszek $^{4}$
}

Published online: 7 April 2020

(C) The Author(s) 2020

\begin{abstract}
The Basic Empathy Scale is widely used to measure cognitive and affective empathy in different age groups. Although empathy is studied throughout the world, research on this important psychological construct in Eastern European populations needs to be increased. In order to accomplish this, validated instruments to measure empathy are needed in this geographic area. This study was conducted to analyze the psychometric properties of the Basic Empathy Scale in Poland. The sample included 1052 children and adolescents aged 9 to 16, enrolled in Primary and Middle schools. This was a cross-sectional study conducted with a survey that was filled in by the participants during their regular classroom hours. Confirmatory Factor Analyses were conducted, together with concurrent validity analyses and comparisons between younger and older participants, and between females and males were undertaken. A final 12-item version of the Basic Empathy Scale was obtained with affective empathy and cognitive empathy factors. The Polish version of the scale showed good psychometric properties. Females scored higher on affective, cognitive and total empathy than males. Younger male participants scored higher on affective, cognitive and total empathy than older male participants. This validated measure of empathy in Polish children and adolescents can be used to study the relation between empathy and both antisocial and prosocial behaviors. In addition, this measure will allow for Poland to be included in cross-country comparisons of empathy and also used to evaluate programs focused on enhancing empathy in Poland.
\end{abstract}

Keywords Affective empathy $\cdot$ Cognitive empathy $\cdot$ Psychometric properties $\cdot$ Children $\cdot$ Adolescents

Empathy is a personal competence that contributes greatly to the initiation and maintenance of desirable interpersonal relationships. Empathy has received great attention in psychological research and practice, and it was found to be related to desirable moral and social functioning (Romera et al. 2019). Empathy has been defined as an emotional response related to other people's emotions and situation that is congruent with other people's emotional states (Eisenberg et al. 1991). Traditionally, empathy is defined by two dimensions: cognitive empathy, described as understanding other people's emotions, and affective empathy, described as experiencing other people's emotional states (Davis 1983; Jolliffe and Farrington

Darrick Jolliffe

d.jolliffe@greenwich.ac.uk

1 Universidad de Córdoba, Avda. San Alberto Magno s/n, 14001 Cordoba, Spain

2 University of Cambridge, Cambridge, UK

3 University of Greenwich, London, UK

4 Akademia Ignatianum w Krakowie, Kraków, Poland
2006). Thus, empathy includes both thinking and feeling in relation to another's emotional state.

Low empathy is an important predictor of antisocial behaviors, and high empathy is an important predictor of prosocial behaviors. Recent meta-analyses showed that perpetrators of bullying (Zych et al. 2019b, c) and perpetrators of cyberbullying (Zych et al. 2019a) scored lower on both cognitive and affective empathy (see Zych et al. 2019b for a review of both meta-analyses). Similarly, other metaanalyses have found that low empathy was related to an increased likelihood of offending (Jolliffe and Farrington 2004; Van Langen et al. 2014).

Regarding prosocial behaviors, meta-analytic findings confirm that children who defend the victims of bullying score high on empathy (Nickerson et al. 2015; Zych et al. 2019b). In addition, in an experimental manipulation, it was found that empathy-induction using an emotional story was related to significantly higher cooperation with other people (Batson and Moran 1999).

Although the causal relationship between empathy and prosocial and antisocial behaviors still needs to be confirmed, increasing empathy is frequently considered to be an important 
component of interventions designed to prevent or reduce antisocial behaviors such as conduct problems (Durlak et al. 2011). For example, in their meta-analyses including 18 randomized controlled trials of empathy training programs, Teding van Berkhout and Malouff (2016) found that empathy training successfully increased later levels of empathy (Hedge's $g=.51$ ), but this was only clearly the case for select populations (university students and health professionals).

In order to examine the relation of empathy to theoretically relevant constructs in different cultures, and changes in empathy which may be the result of empathy-enhancement programs in these cultures, the development of appropriate tools to measure empathy is an essential initial step. The Basic Empathy Scale (BES), designed and validated by Jolliffe and Farrington (2006), is probably the most popular instrument to measure empathy worldwide. According to a recent review focused on the measurement of empathy, up to 2017 (Basto-Pereira and Farrington 2020), this 2006 BES validation study has received almost 800 citations. The original scale consists of 20 items, 11 measuring affective empathy and 9 measuring cognitive empathy. The original instrument, validated with 363 English adolescents, showed good psychometric properties (Jolliffe and Farrington 2006). Example of studies on psychometric properties of the BES in different countries are shown in Table 1.

As displayed in Table 1, most of the studies showed that females scored higher than males on both cognitive and affective empathy. Many studies conducted with children and adolescents found an adequate fit of the original two-factor structure of the BES, including 20 items (Albiero et al. 2009; D'Ambrosio et al. 2009; Cavojova et al. 2012; Jolliffe and Farrington 2006; Pechorro et al. 2015). Nevertheless, most of these studies found fit indices that are commonly considered adequate but not excellent. The recommended cutoff values for indices such as CFI and TLI are close to .95, with errors (e.g., RMSEA) close to .06 (Hu and Bentler 1999). Among the two-factor structure with 20 items, only Albiero et al. (2009) and Pechorro et al. (2015; with adolescent students but not with the incarcerated female subsample) met these strict cutoff criteria. Thus, the two-factor model with 20 items shows good psychometric properties but it seems possible to find a model with a better fit, although the model fit depends greatly on the sample used in each study.

Several studies tested different factor structures of the BES. Among them, a three-factor model with 20 items was described (Herrera-López et al. 2017). Also, two-factor models with a reduced number of items were found to have a good fit (Geng et al. 2012; Heynen et al. 2016; Pechorro et al. 2015; Sánchez-Pérez et al. 2014). Among these studies, the strict cutoff criteria for an excellent fit (Hu and Bentler 1999) were met for a 12-item version with a two-factor structure that showed the best fit (Heynen et al. 2016) and for a 16-item version with a two-factor structure (Geng et al. 2012). Geng et al. (2012) used a sample aged 9 to 18 years old, an age range similar to the participants of the current study. Thus, it is possible that a shorter version of the BES could be more appropriate in certain settings.

The original version of the BES (Jolliffe and Farrington 2006) includes 12 positively worded items and eight reverse worded items. The short version developed by Heynen et al. (2016) with only two reversed items, using a sample of prisoners, showed the best fit indices. Importantly, the authors of this study suggested that some of the reversed items might have not been understood by the participants. Although combining positive and reversed items is common in psychological research, new developments in psychometrics suggest that this might negatively affect the psychometric properties of questionnaires. Suárez-Alvarez et al. (2018) conducted a repeated measures study, in which they administered a selfefficacy questionnaire with positive only, reversed only, and combined-item forms to general population adults. In comparison to the positive only and reversed only forms, the combined-item form with reversed and positive items showed lower discrimination indices, and also had lower reliability and worse fit indices in a confirmatory factor analysis. There seemed to be no differences regarding acquiescence response bias between the three forms. As a result, the authors recommended not using positive and reversed items combined in the same questionnaire.

It is possible that the use of only positively-worded items would improve the psychometric properties of the BES. Moreover, it is important to validate the BES in the geographic areas where research on empathy is at an earlier stage of development. To our knowledge, the BES has not been validated or used in Poland. At the same time, the rates of bullying in Poland are frequently found to be higher than in other countries (Twardowska-Staszek et al. 2018; Zych et al. 2017).

There are only a few measures of empathy that have been validated in Poland. Among them, Kliszcz et al. (2006) validated the Jefferson Scale of Empathy (Hojat et al. 2002). The Jefferson Scale of Empathy is specifically designed to measure empathy of health care providers with their patients. Jankowiak-Siuda et al. (2017) have recently validated the Polish version of the Empathy Quotient (Wakabayashi et al. 2006). This study was conducted with participants aged 15 to 80 , and the psychometric properties of the scale for children and adolescents were not specifically tested. Some studies in Poland used an Internet application which induced either affective or cognitive empathy, finding that cognitive empathy was related to defending the victims of cyberbullying (Barlińska et al. 2018). These studies did not include self-report measures of empathy.

The BES is one of the most frequently used measures of empathy in the world, but it has not been validated in Poland. Empathy is an important psychological construct (e.g., Cohen and Strayer 1996), and it is essential to have a measure validated for Polish children and adolescents. This would make it possible 
Table 1 Psychometric studies of the Basic Empathy Scale in Different Countries

\begin{tabular}{lll}
\hline Study and Country & Participants & Number of Items and Factors \\
\hline Albiero et al. (2009) & 655 adolescents aged 15.13 years & 20 items with a 2-factor \\
Italy & $(\mathrm{SD}=.89), 252$ males and & structure as in Jolliffe and \\
& 403 females. & Farrington (2006).
\end{tabular}

D’Ambrosio et al. (2009)

France

\author{
Čavojová, Sirota, \& \\ Belovičová (2012) \\ Slovakia
}

Geng et al. (2012)

China

Herrera-López et al. (2017)
446 adolescents aged 14.8 years $(\mathrm{SD}=1.14), 250$ females and 196 males. A retest was conducted with 153 adolescents.

426 students (215 males, 210 females) aged $10-16$ years.

1524 children and adolescents aged $9-18$ years $(48.6 \%$ females).
20 items with a 2 -factor structure as in Jolliffe and Farrington (2006).

20 items with a 2 -factor structure as in Jolliffe and Farrington (2006).

Initially: 20 items with a 2-factor structure as in Jolliffe and Farrington (2006).

Final version: 16 items with a 2 -factor structure.

nitially: 20 items with a 2-factor structure as in Jolliffe and Farrington (2006).

Final version: A three factor structure
Psychometric Properties

Confirmatory Factor Analysis: NFI $=.93$, $\mathrm{CFI}=.95 ; \mathrm{RMSEA}=.068 ; \mathrm{SRMR}=.05$; $\mathrm{GFI}=.91 ; \mathrm{AGFI}=.88$.

Cronbach's $\alpha=.87$ (affective $\alpha=.86$, cognitive $\alpha=.74$ )

Females scored higher than males (stronger in affective empathy).

Confirmatory Factor Analysis: $\chi 2(169)=482.14, p<0.01, \mathrm{CFI}=0.78$, SRMSR $=0.063$, RMSEA $=0.068,90 \%$ $\mathrm{CI}=[0.061-0.075], \mathrm{GFI}=0.90$.

Cronbach's $\alpha=0.80$ (affective $\alpha=0.77$, cognitive $\alpha=0.66$ ), temporal stability coefficient $=0.83$.

Females scored higher than males in affective, cognitive and total empathy.

Good test-retest reliability 3-weeks later (total $r=0.66$, affective $r=0.70$, cognitive $r=0.54$ ).

Confirmatory Factor Analysis: $\chi 2$ (169) = $518.82, p<.001 ;$ SRMSR $=0.072$; RMSEA $=0.070 ;$ GFI $=0.884 ;$ AGFI $=$ 0.856 .

Females scored higher than males in affective, cognitive and total empathy.

Confirmatory Factor Analysis with 20 items: $\chi^{2}=1049.31, \mathrm{df}=169, \chi^{2} / \mathrm{df}=6.21$, $\mathrm{RMSEA}=.063, \mathrm{NFI}=.79, \mathrm{NNFI}=.79$, $\mathrm{CFI}=.81, \mathrm{GFI}=.93, \mathrm{AGFI}=.91$.

Confirmatory Factor Analysis after eliminating 4 items: $\chi 2=186.03, \mathrm{df}=89$, $\chi 2 / \mathrm{df}=2.09, \mathrm{RMSEA}=.038, \mathrm{NFI}=.91$, $\mathrm{NNFI}=.93, \mathrm{CFI}=.95, \mathrm{GFI}=.97$, $\mathrm{AGFI}=.95$.

Females scored higher than males in affective, cognitive and total empathy. Older participants scored higher than younger participants. Good test-retest correlations for cognitive $(r=.60)$ and affective $(r=.70)$ subscales. Good Cronbach's alphas (cognitive $\alpha=.72$, affective $\alpha=.73$ total $\alpha=.77)$

Confirmatory Factor Analysis with the original 2-factor structure: $\chi 2 \mathrm{~S}-\mathrm{B}=839.355 ; \chi 2 \mathrm{~S}-\mathrm{B} /(169)=4.967$; $p<0.001 ; \mathrm{NNFI}=0.904 ; \mathrm{CFI}=0.915$; RMSEA $=0.069$ (90\%CI 0.063 to 0.075$)$; SRMR $=0.088 ;$ AIC $=968.962$

Confirmatory Factor Analysis with a 3-factor structure three-factor solution (emotional contagion, cognitive empathy, emotional disengagement) $\mathrm{s}-\mathrm{b} \chi 2=618.163 ; \chi 2 \mathrm{~S}-\mathrm{B} /(167)=3.702$; $\mathrm{p}<0.001 ; \mathrm{NNFI}=0.919 ; \mathrm{CFI}=0.929$; RMSEA $=0.063(90 \%$ CI 0.058 to 0.069$)$; $\mathrm{SRMR}=0.077 ; \mathrm{AIC}=284.163$

Good Cronbach's alphas for the 2-factor model (affective $\alpha=.70$; cognitive $\alpha=0.67$ ) and for the 3 -factor model 
Table 1 (continued)

\begin{tabular}{|c|c|c|c|}
\hline Study and Country & Participants & Number of Items and Factors & Psychometric Properties \\
\hline & & & $\begin{array}{l}\text { (emotional contagion } \alpha=.66 \text {; cognitive } \\
\alpha=0.69 \text {; emotional-disengagement } \alpha=.80 \text { ). }\end{array}$ \\
\hline \multirow[t]{3}{*}{$\begin{array}{l}\text { Heynen et al. (2016) } \\
\text { Germany }\end{array}$} & \multirow[t]{3}{*}{$\begin{array}{l}94 \text { incarcerated young males, } \\
14-26 \text { years old. }\end{array}$} & \multirow{2}{*}{$\begin{array}{l}\text { Initially: } 20 \text { items with a } \\
\text { 2-factor structure as in } \\
\text { Jolliffe and Farrington (2006). }\end{array}$} & $\begin{array}{l}\text { Confirmatory Factor Analysis with } 20 \text { items: } \\
\text { RMSEA }=.101 ; \mathrm{CFI}=.753 ; \mathrm{TLI}=.619 .\end{array}$ \\
\hline & & & $\begin{array}{l}\text { Confirmatory Factor Analysis with } 12 \text { items: } \\
\text { RMSEA }=.038 ; \text { CFI }=.977 ; \text { TLI }=.969 .\end{array}$ \\
\hline & & $\begin{array}{l}\text { Final version: } 12 \text { items } \\
\text { with a } 2 \text {-factor structure }\end{array}$ & $\begin{array}{l}\text { Good Cronbach's alphas (affective } \alpha=.71 \text {, } \\
\text { cognitive } \alpha=.78 \text { ). }\end{array}$ \\
\hline \multirow[t]{3}{*}{$\begin{array}{l}\text { Jolliffe and Farrington (2006) } \\
\text { The UK }\end{array}$} & \multirow{3}{*}{$\begin{array}{l}363 \text { adolescents }(194 \text { males, } \\
169 \text { females }), \text { Mean } \\
\text { age }=14.8(\mathrm{SD}=0.48)\end{array}$} & \multirow[t]{3}{*}{20 items with a 2 -factor structure } & $\begin{array}{l}\text { Confirmatory Factor Analysis with } 20 \text { items: } \\
\text { GFI }=0.89, \mathrm{AGFI}=0.86, \mathrm{RMS}=0.06\end{array}$ \\
\hline & & & $\begin{array}{l}\text { Females scored higher than males in } \\
\text { affective and cognitive empathy. }\end{array}$ \\
\hline & & & Good concurrent validity. \\
\hline \multirow[t]{4}{*}{$\begin{array}{l}\text { Pechorro et al. (2015) } \\
\text { Portugal }\end{array}$} & \multirow[t]{4}{*}{$\begin{array}{l}377 \text { females aged } 14-19 \text { years } \\
\text { among which } 103 \text { were } \\
\text { incarcerated and } 274 \text { were } \\
\text { a school sample. }\end{array}$} & $\begin{array}{l}\text { Initially: } 20 \text { items with a 2-factor } \\
\text { structure as in Jolliffe and } \\
\text { Farrington (2006). }\end{array}$ & $\begin{array}{l}\text { Confirmatory Factor Analysis with } 20 \text { items } \\
\text { in the school sample: S-B } \times 2 \mathrm{df}=2.83 \text {, } \\
\text { IFI }=0.96, \text { CFI }=0.96 \text { RMSEA } \\
(90 \% \mathrm{CI})=0.08(0.07-0.09) \text { AIC }=138.18 .\end{array}$ \\
\hline & & \multirow[t]{3}{*}{$\begin{array}{l}\text { Final: } 20 \text { items in the school } \\
\text { sample, } 18 \text { items in } \\
\text { incarcerated females. }\end{array}$} & $\begin{array}{l}\text { Confirmatory Factor Analysis with } 20 \text { items } \\
\text { in incarcerated females: S-B } \times 2 / \mathrm{df}=2.40 \text {, } \\
\mathrm{IFI}=0.84, \mathrm{CFI}=0.84, \mathrm{RMSEA} \\
(90 \% \mathrm{CI})=0.12(0.10-0.13), \mathrm{AIC}=65.93\end{array}$ \\
\hline & & & $\begin{array}{l}\text { Confirmatory Factor Analysis with } 18 \text { items in } \\
\text { incarcerated females: } \mathrm{S}-\mathrm{B} \times 2 / \mathrm{df}=2.53 \text {, } \\
\text { IFI }=0.87, \mathrm{CFI}=0.86, \mathrm{RMSEA} \\
(90 \% \mathrm{CI})=0.12(0.11-0.14), \mathrm{AIC}=68.96 .\end{array}$ \\
\hline & & & $\begin{array}{l}\text { Good Cronbach's alphas (school: affective } \\
\alpha=0.85 \text {, cognitive } \alpha=0.93 \text {, total } \alpha=0.90 \\
\text { incarcerated affective } \alpha=0.81 \text {, cognitive } \\
\alpha=0.86 \text {, total } \alpha=0.82 \text { ) }\end{array}$ \\
\hline \multirow[t]{3}{*}{ Sánchez-Pérez et al. (2014) } & \multirow[t]{3}{*}{$\begin{array}{l}290 \text { children ( } 145 \text { males, } 145 \\
\text { females) aged } 8-12 \text { years }\end{array}$} & \multirow[t]{2}{*}{$\begin{array}{l}\text { Initially: } 20 \text { items with a } 2 \text {-factor } \\
\text { structure as in Jolliffe and } \\
\text { Farrington (2006). }\end{array}$} & $\begin{array}{l}\text { Confirmatory Factor Analysis with } 18 \text { items: } \\
\chi 2 / \mathrm{df}=1.52, \mathrm{CFI}=0.93, \mathrm{TLI}=0.92 \\
\mathrm{RMSEA}=0.04, \mathrm{SRMR}=0.07\end{array}$ \\
\hline & & & $\begin{array}{l}\text { Acceptable Cronbach's alpha (affective } \\
\alpha=0.66 \text {, cognitive } \alpha=0.70 \text { ). }\end{array}$ \\
\hline & & $\begin{array}{l}\text { Final: } 18 \text { items with } \\
\text { a 2-factor structure }\end{array}$ & No gender differences were found. \\
\hline
\end{tabular}

to obtain a measure that can be used to evaluate programs to enhance empathy, and to understand if the relation of empathy with prosocial and antisocial behaviors in Poland is similar to the relations among these variables found in other countries. Therefore, the objective of this study is to analyze the psychometric properties of the Polish version of the BES using a broad sample of children and adolescents. The psychometric properties of the questionnaire will be tested using the 20 -item version and a short version that includes only the positively-worded items. Given that empathy is related to desirable moral functioning (e.g., Romera et al. 2019), social and emotional competencies and prosocial behaviors (e.g., Nickerson et al. 2015) concurrent validity is tested through correlations with these constructs. It was hypothesized that the Polish version of the BES would have good psychometric properties.

\section{Method}

\section{Participants}

A total number of 1052 students aged 9 to 16 years $(M=12.53$, $S D=1.98 ; 54.4 \%$ females) participated in this study. Schools were located in the Lesser Poland geographic area, four of these were in a large city and two were in smaller towns. Students were enrolled in four Primary Schools, Grades 4 to $7(N=580)$ and two Middle Schools, Grades 2 and $3(N=472)$. All the participants were Caucasian with Polish nationality.

\section{Procedure}

This was a cross-sectional study conducted using a survey method-approach. The BES was translated into Polish by the first 
author (a Polish native speaker), reviewed by the last author (also a Polish native speaker) and back-translated into English by an official translation service. The final versions were compared, and minor disagreements resolved. The minor disagreements were related to vocabulary that could mostly be interpreted as synonyms.

Schools were selected by convenience sampling through the head teachers who were invited to participate in this study. These schools were then contacted, and all agreed to participate in the survey. Within each classroom, students were informed about the objective of this study by a researcher and asked to fill in the survey. Participation was voluntary and anonymous, and participants had the right to decline or withdraw from the study at any point. Students filled in a pen and paper survey during their regular classroom hours, supervised by the researchers of this project who delivered and collected the questionnaires. None of the students declined to participate or withdrew their consent. The study met all national and international ethical standards, including the Declaration of Helsinki and the data protection regulations.

\section{Instruments}

Empathy was measured using the Basic Empathy Scale (Jolliffe and Farrington 2006) translated into Polish. The original and the Polish version of the BES use a 5-point Likert response scale ranging from 1 (totally disagree) to 5 (totally agree). The original scale contains 20 items: 11 items focused on affective empathy and 9 items focused on cognitive empathy. The final Polish version included 12 positive-worded items, with six focused on affective empathy (e.g., feeling sad after being with a friend who was sad) and six focused on cognitive empathy (e.g., understanding friend's happiness). The instrument showed good psychometric properties described in the results section.

Social and emotional competencies were measured using the Social and Emotional Competencies Questionnaire (SECQ) by Zych et al. (2018). This instrument ( $\alpha=.90$, in the current sample) contains 16 items with a 5-point Likert response scale ranging from 1 (strongly disagree) to 5 (strongly agree). It includes four factors: Self-awareness $(\alpha=.78$; e.g., "I am aware of the thoughts that influence my emotions"), Self-motivation and management $(\alpha=.77$; e.g., "I pursue my objectives despite the difficulties"), Social-awareness and prosocial behavior ( $\alpha=.79$; e.g., "I usually know how to help others who need that") and Responsible decision making ( $\alpha=$.78; e.g., "I usually consider advantages and disadvantages of each option before I make decisions"). The CFA showed a good fit of the current data to this four-factor model $\left(\mathrm{S} / \mathrm{B} \chi^{2}=291.1784 ; d f=98 ; p<.001 ; \mathrm{NFI}=.98 ; \mathrm{NNFI}=.98\right.$; $\mathrm{CFI}=.99 ; \mathrm{RMSEA}=.047 ; 90 \% \mathrm{CI}=.041-.053)$.

Moral disengagement was measured using The Mechanisms of Moral Disengagement Scale (Bandura et al. 1996). This instrument $(\alpha=.93)$ includes 32 items with a 5-point Likert response scale ranging from 1 (totally disagree) to 5 (totally agree) distributed across 4 domains: Dehumanization $(\alpha=.78 ; 8$ items, e.g., "Some people deserve to be treated as animals"), Minimizing consequences ( $\alpha=.67 ; 4$ items, e.g., "Teasing someone does not really hurt them"), Reconstruction ( $\alpha=.79 ; 12$ items, e.g., "It is alright to beat someone who bad mouths your family"), and Disconnecting agency ( $\alpha=.76 ; 8$ items, e.g., "If kids are living under bad conditions they cannot be blamed for behaving aggressively"). The CFA confirmed the four factor structures showing an adequate fit of the current data $\left(\mathrm{S} / \mathrm{B} \chi^{2}=1879.7569 ; d f=458 ; p<.001 ; \mathrm{NFI}=.90\right.$; $\mathrm{NNFI}=.92 ; \mathrm{CFI}=.92 ; \mathrm{RMSEA}=.091 ; 90 \% \mathrm{CI}=.087-.096)$.

A short 19-item version was developed for Primary Education after eliminating the items that were difficult to understand for Primary School children, with a 5-point Likert response scale ranging from 1 (totally disagree) to 5 (totally agree) distributed in three domains: Dehumanization ( $\alpha=.82 ; 7$ items), Minimizing consequences ( $\alpha=.74 ; 4$ items), and Reconstruction ( $\alpha=.83 ; 8$ items). The CFA for the three-factor model indicates a good fit of the data $(\mathrm{S} / \mathrm{B}$ $\chi^{2}=664.4819 ; d f=149 ; p<.001 ; \mathrm{NFI}=.97 ; \mathrm{NNFI}=.97 ;$ $\mathrm{CFI}=.98 ; \mathrm{RMSEA}=.085 ; 90 \% \mathrm{CI}=.079-.092$ ).

\section{Data Analysis}

First, a Confirmatory Factor Analysis (CFA) with maximum likelihood, robust method and polychoric correlations (SatorraBentler chi-square) was performed with EQS. 6.2. This was done with a 20-item model based on the original version of the BES (Jolliffe and Farrington 2006). Model fit was tested taking into account a combination of different indices such as the Normed Fit Index (NFI) ( $\geq .90)$, the Non-Normed Fit Index (NNFI) ( $\geq .90)$, the Comparative Fit Index (CFI) ( $\geq .90)$ and the Root Mean Square Error Approximation (RMSEA) $(\leq .08)$ (Bentler, 1990). Factor loadings were examined and items with low factor loadings (lower than .20) were eliminated, and another Confirmatory Factor Analysis was run. Item-total correlation matrix was examined to check if all the items of the scale were correlated in the expected direction. Items with non-significant correlations and correlations in an unexpected direction were eliminated obtaining a short version of the BES with positively-worded items only. Another Confirmatory Factor Analysis was run and fit indices of all the models were compared to choose the model with the best fit.

Descriptive statistics were calculated using the PASW Statistics 20 software. Cronbach's alphas were calculated for each factor and the total scale. Pearson item-total correlations and interitem correlations were also calculated. Concurrent validity was tested using Pearson correlations among the BES, Moral disengagement and Social and Emotional Competencies. Empathy was expected to be related to low Moral disengagement and high level of Social and Emotional Competencies. Differences between males and females, and younger versus 
older participants, were tested using the Student's $t$ test. To estimate the construct reliability, composite reliability (CR) and average variance extracted (AVE) were computed. The cut-off points used for these indices are usually .70 for $\mathrm{CR}$ and .50 for AVE.

\section{Results}

\section{Factor Structure and Items of the BES in Polish Children and Adolescents}

A confirmatory factor analysis using the original 20-item twofactor structure of the BES showed a poor fit to the data for Primary Education participants $(\mathrm{S} / \mathrm{B}$ chi-square $=794.52, \mathrm{df}=$ $169, p<.01, \mathrm{CFI}=.69, \mathrm{NFI}=.64$. RMSEA $=.09$ ) and for Middle Education participants (S/B chi-square $=1528.12$, df $=$ $169, p<.01, \mathrm{CFI}=.66, \mathrm{NFI}=.63$. RMSEA $=.14$ ). Thus, other models were tested to find a better fit to the data.

Factor loadings of items 1, 6 and 13 (all negativelyworded) were below .20 in both Primary and Middle Education subsamples. Model fit improved after eliminating these items for Primary Education participants (S/B chisquare $=777.68, \mathrm{df}=118, p<.01, \mathrm{CFI}=.88, \mathrm{NFI}=.86$. RMSEA $=.11)$ and for Middle Education participants $(\mathrm{S} / \mathrm{B}$ chi-square $=972.77, \mathrm{df}=118, p<.01, \mathrm{CFI}=.76, \mathrm{NFI}=.74$, RMSEA = .13). Nevertheless, the model fit was still poor.

Item-total correlation matrix and interitem correlation analyses showed some further concerns regarding the negativelyworded items. Item 7 (negative) had nonsignificant correlations with items 9 and 10; item 8 (negative) had nonsignificant correlations with items 4, 9 and 11; item 19 (negative) had nonsignificant correlations with item 17 , and item 20 (negative) had nonsignificant correlations with items 4, 5, 11, 15 and 17. In the Middle Education sample, all the negative worded items had loadings below .40. In the Primary Education sample, negatively-worded items such as 7, 8, and 20 had loadings below .40. Thus, a model without the negatively-worded items was tested.

Alternatively, a 12-item model without the negatively-worded items showed a good fit to data in Primary Education (S/B chisquare $=177.14, \mathrm{df}=53, p<.01, \mathrm{CFI}=.97, \mathrm{NFI}=.96$, RMSEA $=.07)$ and in Middle Education $(\mathrm{S} / \mathrm{B}$ chi-square $=$ 203.02, $\mathrm{df}=53, p<.01, \mathrm{CFI}=.94, \mathrm{NFI}=.93$, RMSEA $=.08$ ). In this case, all the factor loadings were above .40 (see Fig. 1). Thus, based on the fit indices and theoretical basis, the two-factor model with 12 items was considered the best.

\section{Reliability of the BES in Polish Children and Adolescents}

The Polish version of the BES had very good Cronbach's alpha values for affective (Primary $\alpha=.75$, Middle $\alpha=.76$ ),

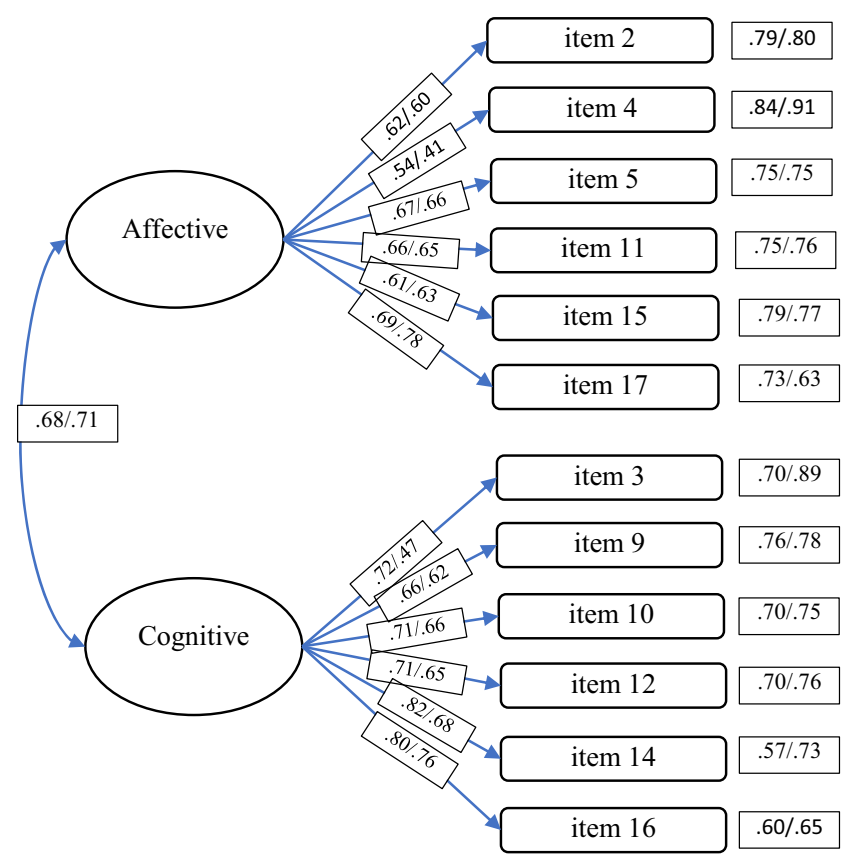

Note: Primary/Middle Education coefficients

Fig. 1 Confirmatory Factor Analysis of the Basic Empathy Scale in Poland

cognitive (Primary $\alpha=.84$, Middle $\alpha=.77$ ) and total empathy (Primary $\alpha=.85$, Middle $\alpha=.84$ ). The Average Variance Extracted in the Primary School sample was .47 and in the Secondary School sample was .41. The Composite Reliability in the Primary School sample was .91 and in the Middle School sample was .89.

\section{Empathy in Males and Females in Primary and Middle Education}

Table 2 shows that affective, cognitive and total empathy were higher in Primary Education compared to Middle Education. It also shows that affective, cognitive and total empathy were higher for females compared to males. Gender differences were consistent in both Primary and Middle Education. Nevertheless, the lower levels of empathy in Primary compared to Middle education was only significant for males. Thus, older males have less empathy, but there were no differences for females.

\section{Relations among Empathy, Moral Disengagement and Social and Emotional Competencies}

Concurrent validity was tested by checking if empathy was related to social and emotional competencies and to moral disengagement. These relations were statistically significant and were in the expected direction, showing that empathy was positively related to high social and emotional competencies and low moral disengagement (see Table 3). The 
strongest relations were found between high affective empathy and high social awareness and prosociality, and between high cognitive empathy and a high total score in social and emotional competencies.

\section{Discussion}

Empathy is an important social and emotional skill that is related to low antisocial behavior (Jolliffe and Farrington 2004) and high prosocial behavior (Nickerson et al. 2015). As a result, many social and emotional learning programs target increasing empathy as a way of increasing desirable behavior and social cohesion (Durlak et al. 2011). Nevertheless, research focused on empathy is not equally advanced around the world and there are some geographic areas, such as Poland, where studies on empathy are urgently needed.

The objective of this study was to test the psychometric properties of the BES in Poland using a broad sample of Polish children and adolescents. The BES is one of the most popular measures of empathy in the world (see Basto-Pereira and Farrington 2019 for a review). This measure had not been validated in Poland. To our knowledge, this is the first study that validated a measure of empathy in Polish children and adolescents. Thus, we believe that the current results are useful in advancing knowledge about empathy in an understudied geographic area.

In this study, an original 20 -item version of the BES (Jolliffe and Farrington 2006) was tested, but this factor structure did not show a good fit to the data. Based on other studies that used a shorter version (e.g., Geng et al. 2012; Heynen et al. 2016), and on statistical analyses of the items, a 12item version of the BES was produced. Some studies suggest that the inclusion of both positively-worded items and negatively-worded items in a questionnaire decreases its psychometric properties (Suárez Álvarez et al., 2018). The final Polish version of the BES, with the best psychometric properties, includes only positively-worded items. Thus, it is possible that the participants had difficulties in understanding the negatively-worded items or the Likert response-scale for these items. The Polish 12-item version of the BES showed very good psychometric properties for Primary School children and Middle School adolescents.

Some gender differences were found regarding affective and cognitive empathy in Polish children and adolescents. Females scored higher than males in Primary and Middle school subsamples, in affective and cognitive empathy. Perceived affective and cognitive empathy were stable in females but decreased with age in males. Empathy was found to be related to theoretically similar constructs such as low moral disengagement and high social and emotional competencies. Nevertheless, these relations were stronger in males than in 
Table 3 Pearson Correlations between Empathy (final scales), Moral Disengagement and Social and Emotional Competencies

\begin{tabular}{|c|c|c|c|c|c|c|c|c|c|}
\hline & $\begin{array}{l}\text { Affective } \\
\text { Empathy }\end{array}$ & $\begin{array}{l}\text { Cognitive } \\
\text { Empathy }\end{array}$ & $\begin{array}{l}\text { Total } \\
\text { Empathy }\end{array}$ & $\begin{array}{l}\text { Moral } \\
\text { Disengagement }\end{array}$ & $\begin{array}{l}\text { Total Social } \\
\text { Emotional } \\
\text { Competencies }\end{array}$ & $\begin{array}{l}\text { Self- } \\
\text { awareness }\end{array}$ & $\begin{array}{l}\text { Self- } \\
\text { management } \\
\text { and } \\
\text { Motivation }\end{array}$ & $\begin{array}{l}\text { Social } \\
\text { Awareness } \\
\text { and } \\
\text { Prosociality }\end{array}$ & $\begin{array}{l}\text { Responsible } \\
\text { Decision } \\
\text { Making }\end{array}$ \\
\hline Affective Empathy & 1 & $.54 * *$ & $.89 * *$ & $-.13 * *$ & .04 & .00 & -.02 & $.17 * *$ & .01 \\
\hline Cognitive Empathy & $.54^{* *}$ & 1 & $.86^{* *}$ & $-.16^{* *}$ & $.31 * *$ & $.22 * *$ & $.15^{* *}$ & $.32 * *$ & $.21 * *$ \\
\hline Total Empathy & $.87^{* *}$ & $.88^{* *}$ & 1 & $-.16^{* *}$ & $.20 * *$ & $.14 * *$ & .08 & $.28 * *$ & $.12 * *$ \\
\hline $\begin{array}{l}\text { Moral } \\
\text { Disengagement }\end{array}$ & $-.12^{*}$ & $-.15^{* *}$ & $-.16^{* * *}$ & 1 & $-.33^{* *}$ & $-.19^{* *}$ & $-.21 * *$ & $-.36^{* *}$ & $-.28 * *$ \\
\hline $\begin{array}{l}\text { Total Social and } \\
\text { Emotional } \\
\text { competencies }\end{array}$ & $.24 * *$ & $.54^{* *}$ & $.45^{* *}$ & $-.21^{* *}$ & 1 & $.75 * *$ & $.79^{* *}$ & $.86^{* *}$ & $.75^{* *}$ \\
\hline Self-awareness & .07 & $.31^{* * *}$ & $.21 * *$ & $-.15^{* *}$ & $.77^{* *}$ & 1 & $.47 * *$ & $.50^{* *}$ & $.40 * *$ \\
\hline $\begin{array}{r}\text { Self-management } \\
\text { and motivation }\end{array}$ & $.18^{* *}$ & $.40 * *$ & $.33^{* *}$ & -.05 & $.82^{* *}$ & $.58^{* *}$ & 1 & $.56^{* *}$ & $.46^{* *}$ \\
\hline $\begin{array}{l}\text { Social awareness } \\
\text { and prosociality }\end{array}$ & $.34 * *$ & $.50 * *$ & $.48^{* * *}$ & $-.25^{*}$ & $.89^{* * *}$ & $.57^{* *}$ & $.67^{* *}$ & 1 & $.53^{* *}$ \\
\hline $\begin{array}{l}\text { Responsible decision } \\
\text { making }\end{array}$ & $.17^{* *}$ & $.42 * *$ & $.34^{* *}$ & $-.20^{* *}$ & $.75^{* *}$ & $.43^{* *}$ & $.48^{* *}$ & $.58^{* *}$ & 1 \\
\hline
\end{tabular}

${ }^{*} p<.05,{ }^{*} p<.01$, Females above the diagonal, males below the diagonal

females. Previous research found that females tend to have more advanced perceptions of social and emotional competencies (Zych et al. 2018), and therefore, it is possible that they can distinguish between empathy and similar constructs whereas males treat them all as a single, less complex construct. Future studies should examine these possibilities.

Given that the rates of antisocial behaviors such as bullying in Poland are relatively high (Twardowska-Staszek et al. 2018), programs to decrease these behaviors are urgently needed. Increasing empathy should be a component of these programs and the current study is especially useful for the evaluation of these programs, that should be specifically adapted to Polish culture. For example, compared to other countries, Poland is a country with medium-high individualistic culture and medium-high emotional expressivity endorsement (Matsumoto et al. 2008). Thus, it is reasonable to suggest that programs to promote empathy in Poland should be based on both individual and social values, and can use relatively high, but not exaggerated, expressions of empathy based on emotional expressivity culture in Poland. Future studies could also include cross-national comparisons to study similarities and differences in the relation between empathy and antisocial or prosocial behaviors in Poland and other geographic areas. This could be useful for the prevention and intervention in these behaviors.

This study has several strengths, such as the use of a broadly validated questionnaire with a large sample of Polish children and adolescents. Nevertheless, it also has some limitations. Given that the Polish version of the BES only includes positively-worded items, it could be useful to conduct future studies that control for social desirability or acquiescence response bias. Future research could also use empathy measures that do not use self-reports, for example, other-reports focused on behavioral expressions of empathy. Despite these limitations, the current study is an important step towards filling the gaps in knowledge regarding empathy in Poland.

Given that research on empathy is not equally advanced around the world, and studies in Poland were urgently needed, the current study is an important contribution to the field. The Polish version of the Basic Empathy Scale has good psychometric properties and it can become a very useful tool for researchers and practitioners in psychology in Poland.

\section{Compliance with ethical standards}

All procedures performed in studies involving human participants were in accordance with the ethical standards of the institutional and/or national research committee and with the 1964 Helsinki declaration and its later amendments or comparable ethical standards.

Conflict of interest All the authors declare that they have no conflict of interest.

Open Access This article is licensed under a Creative Commons Attribution 4.0 International License, which permits use, sharing, adaptation, distribution and reproduction in any medium or format, as long as you give appropriate credit to the original author(s) and the source, provide a link to the Creative Commons licence, and indicate if changes were made. The images or other third party material in this article are included in the article's Creative Commons licence, unless indicated otherwise in a credit line to the material. If material is not included in the article's Creative Commons licence and your intended use is not permitted by statutory regulation or exceeds the permitted use, you will need to obtain 
permission directly from the copyright holder. To view a copy of this licence, visit http://creativecommons.org/licenses/by/4.0/.

\section{References}

Albiero, P., Matricardi, G., Speltri, D., \& Toso, D. (2009). The assessment of empathy in adolescence: A contribution to the Italian validation of "the Basic Empathy Scale". Journal of Adolescence, 32, 393-408. https://doi.org/10.1016/j.adolescence.2008.01.001 .

Bandura, A., Barbaranelli, C., Caprara, G. V., \& Pastorelli, C. (1996). Mechanisms of moral disengagement in the exercise of moral agency. Journal of Personality and Social Psychology, 71, 364-374. https://doi.org/10.1037/0022-3514.71.2.364.

Barlińska, J., Szuster, A., \& Winiewski, M. (2018). Cyberbullying among adolescent bystanders: Role of affective versus cognitive empathy in increasing prosocial cyberbystander behavior. Frontiers in Psychology, 9, 799. https://doi.org/10.3389/fpsyg.2018.00799.

Basto-Pereira, M. \& Farrington, D.P. (2020) The Basic Empathy Scale: psychometric properties and contributions to the understanding of antisocial behaviour. In Jolliffe, D. and Farrington, D.P. (Eds.) Empathy versus Offending, Aggression and Bullying: Advancing Knowledge using the Basic Empathy Scale. Abingdon: Routledge

Batson, C. D., \& Moran, T. (1999). Empathy-induced altruism in a prisoner's dilemma. European Journal of Social Psychology, 29, 909 924. https://doi.org/10.1002/(SICI)1099-0992(199911)29:7<909:: AID-EJSP965>3.0.CO;2-L.

Cavojova, V., Sirota, M., \& Belovicova, Z. (2012). Slovak validation of the basic empathy scale in pre-adolescents. Studia Psychologica, 54(3), 195-208.

Cohen, D., \& Strayer, J. (1996). Empathy in conduct-disordered and comparison youth. Developmental Psychology, 32, 988-998. https://doi.org/10.1037/0012-1649.32.6.988.

D’Ambrosio, F., Olivier, M., Didon, D., \& Besche, C. (2009). The basic empathy scale: A French validation of a measure of empathy in youth. Personality and Individual Differences, 46, 160-165. https://doi.org/10.1016/j.paid.2008.09.020.

Davis, M. H. (1983). Measuring individual differences in empathy: Evidence for a multidimensional approach. Journal of Personality and Social Psychology, 44, 113-126. https://doi.org/10.1037/00223514.44.1.113.

Durlak, J. A., Weissberg, R. P., Dymnicki, A. B., Taylor, R. D., \& Schellinger, K. B. (2011). The impact of enhancing students' social and emotional learning: A meta-analysis of school-based universal interventions. Child Development, 82, 405-432. https://doi.org/10. 1111/j.1467-8624.2010.01564.x.

Eisenberg, N., Shea, C. L., Carlo, G., \& Knight, G. P. (1991). Empathyrelated responding and cognition: A "chicken and the egg" dilemma. In W. M. Kurtines (Ed.), Handbook of moral behavior and development, Research (Vol. 2, pp. 63-88). Hillsdale: Erlbaum.

Geng, Y., Xia, D., \& Qin, B. (2012). The basic empathy scale: A Chinese validation of a measure of empathy in adolescents. Child Psychiatry and Human Development, 43, 499-510. https://doi.org/10.1007/ s10578-011-0278-6.

Herrera-López, M., Gómez-Ortiz, O., Ortega-Ruiz, R., Jolliffe, D., \& Romera, E. M. (2017). Suitability of a three-dimensional model to measure empathy and its relationship with social and normative adjustment in Spanish adolescents: A cross-sectional study. BMJ Open, 7, e015347. https://doi.org/10.1136/bmjopen-2016-015347.

Heynen, E. E., Van der Helm, G. P., Stams, G. M., \& Korebrits, A. M. (2016). Measuring empathy in a German youth prison: A validation of the German version of the basic empathy scale (BES) in a sample of incarcerated juvenile offenders. Journal of Forensic Psychology
Practice, 16, 336-346. https://doi.org/10.1080/15228932.2016. 1219217.

Hojat, M., Gonnella, J. S., Nasca, T. J., Mangione, S., Veloksi, J. J., \& Magee, M. (2002). The Jefferson scale of physician empathy: Further psychometric data and differences by gender and specialty at item level. Academic Medicine, 77(10 Suppl), S58-S60.

$\mathrm{Hu}, \mathrm{L} . \mathrm{T}$., \& Bentler, P. M. (1999). Cutoff criteria for fit indexes in covariance structure analysis: Conventional criteria versus new alternatives. Structural Equation Modeling, 6, 1-55. https://doi.org/ 10.1080/10705519909540118.

Jankowiak-Siuda, K., Kantor-Martynuska, J., Siwy-Hudowska, A., Śmieja, M., Dobrołowicz-Konkol, M., Zaraś-Wieczorek, I., \& Siedler, A. (2017). Psychometric properties of the polish adaptation of short form of the empathy quotient (EQ-short). Psychiatria Polska, 51, 197-734. https://doi.org/10.12740/PP/64270.

Jolliffe, D., \& Farrington, D. P. (2004). Empathy and offending: A systematic review and meta-analysis. Aggression and Violent Behavior, 9, 441-476. https://doi.org/10.1016/j.avb.2003.03.001.

Jolliffe, D., \& Farrington, D. P. (2006). Development and validation of the basic empathy scale. Journal of Adolescence, 29, 589-611. https://doi.org/10.1016/j.adolescence.2005.08.010.

Kliszcz, J., Nowicka-Sauer, K., Trzeciak, B., Nowak, P., \& Sadowska, A. (2006). Empathy in health care providers - Validation study of the polish version of the Jefferson scale of empathy. Advances in Medical Sciences, 51, 219-225.

Matsumoto, D., Yoo, S. H., Fontaine, J., \& Gross, E. (2008). Mapping expressive differences around the world: The relationship between emotional display rules and individualism versus collectivism. Journal of Cross-Cultural Psychology, 39, 55-74. https://doi.org/ 10.1177/0022022107311854.

Nickerson, A. B., Aloe, A. M., \& Werth, J. M. (2015). The relation of empathy and defending in bullying: A meta-analytic investigation. School Psychology Review, 44, 372-390. https://doi.org/10.17105/ spr-15-0035.1.

Pechorro, P., Ray, J. V., Salas-Wright, C. P., Maroco, J., \& Goncalves, R. A. (2015). Adaptation of the basic empathy scale among a Portuguese sample of incarcerated juvenile offenders. Psychology, Crime \& Law, 21, 699-714. https://doi.org/10.1080/1068316X. 2015.1028546

Romera, E. M., Casas, J. A., Gómez-Ortiz, O., \& Ortega-Ruiz, R. (2019). Moral domain as a risk and protective factor against bullying. An integrating perspective review on the complexity of morality. Aggression and Violent Behavior, 45, 75-82. https://doi.org/10. 1016/j.avb.2018.07.005.

Sánchez-Pérez, N., Fuentes, L. J., Jolliffe, D., \& González-Salinas, C. (2014). Assessing children's empathy through a Spanish adaptation of the basic empathy scale: Parent's and child's report forms. Frontiers in Psychology, 5, 1438. https://doi.org/10.3389/fpsyg. 2014.01438.

Suárez-Alvarez, J., Pedrosa, I., Lozano Fernández, L. M., García-Cueto, E., Cuesta, M., \& Muñiz, J. (2018). Using reversed items in Likert scales: A questionable practice. Psicothema, 30, 149-158. https:// doi.org/10.7334/psicothema2018.33.

Teding van Berkhout, E., \& Malouff, J. M. (2016). The efficacy of empathy training: a meta-analysis of randomized controlled trials. Journal of Counseling Psychology, 63, 32-41. https://doi.org/10. 1037/cou0000093.

Twardowska-Staszek, E., Zych, I., \& Ortega-Ruiz, R. (2018). Bullying and cyberbullying in polish elementary and middle schools: Validation of questionnaires and nature of the phenomena. Children and Youth Services Review, 95, 217-225. https://doi.org/ 10.1016/j.childyouth.2018.10.045.

Van Langen, M. A., Wissink, I. B., Van Vugt, E. S., Van der Stouwe, T., \& Stams, G. J. J. M. (2014). The relation between empathy and offending: A meta-analysis. Aggression and Violent Behavior, 19, 179-189. https://doi.org/10.1016/j.avb.2014.02.003. 
Wakabayashi, A., Baron-Cohen, S., Wheelwright, S., Goldenfeld, N., Delaney, J., Fine, D., et al. (2006). Development of short forms of the empathy quotient (EQ) and the systemizing quotient (SQ). Personality and Individual Differences, 41, 929-940. https://doi. org/10.1016/j.paid.2006.03.017.

Zych, I., Ortega-Ruiz, R., \& Llorent, V. J., (2017). Nature and dynamics of peer violence in Polish upper secondary schools. Social Psychology of Education, 20, 427-443. https://doi.org/10.1007/ s11218-017-9378-x

Zych, I., Ortega-Ruiz, R., Munoz-Morales, R., \& Llorent, V. J. (2018). Dimensions and psychometric properties of the social and emotional competencies questionnaire (SEC-Q) in youth and adolescents. Revista Latinoamericana de Psicología, 50, 98-106. https://doi. org/10.14349/rlp.2018.v50.n2.3.

Zych, I., Baldry, A. C., Llorent, V. J., \& Farrington, D. P. (2019a). Are children involved in cyberbullying low on empathy? A systematic review and meta-analysis of research on empathy in different cyberbullying roles. Aggression and Violent Behavior, 45, 83-97. https://doi.org/10.1016/j.avb.2018.03.004.

Zych, I., Farrington, D. P., \& Ttofi, M. M. (2019b). Protective factors against bullying and cyberbullying: A systematic review of metaanalyses. Aggression and Violent Behavior, 45, 4-19. https://doi. org/10.1016/j.avb.2018.06.008.

Zych, I., Ttofi, M. M., \& Farrington, D. P. (2019c). Empathy and callousunemotional traits in different bullying roles: A systematic review and meta-analysis. Trauma, Violence, \& Abuse, 20, 3-21. https:// doi.org/10.1177/1524838016683456.

Publisher's Note Springer Nature remains neutral with regard to jurisdictional claims in published maps and institutional affiliations. 